\title{
Perineal Colostomy Post Amputation of Rectum
}

\author{
Ingrid Melo Amaral ${ }^{1,2}$, Elvis Vargas Castillo ${ }^{1,3 *}$, Arisel Domínguez ${ }^{1}$, Sthephfania López ${ }^{1}$, Daniel \\ Chiantera $^{1}$, Mariangela Pérez Paz $^{1}$ and Jenils Daniela Coacuto ${ }^{1}$ \\ ${ }^{1}$ Department of Coloproctology, Hospital Domingo Luciani, Spain \\ ${ }^{2}$ Department of Coloproctology, University Hospital of Clinicas, Paraguay \\ ${ }^{3}$ Department of Coloproctology, University Hospital Dexeus, Spain
}

\section{Introduction}

The operation described by Miles in 1908, an effective method in the radical treatment of tumors of the anus and lower rectum [1], and with better survival, leaves the stigma of the definitive iliac colostomy that leads to various psychosocial disorders [2]. Seeking to reduce social and family rejection, in addition to gas elimination and lack of control of the stools by the absence of sphincter, several methods of stools retention have been described [3-6]. Dr. Lázaro Da Silva, in Brazil, made the first perineal valve colostomy in 1991, when performing 2 to 3 extra-mucosal circular seromiotomies with invaginating seromuscular synthesis, with the meso-redundant occupying the pelvis, the distal valve stayed extra peritoneal and the proximal fixed to the promontory, this prevents or delays the excretion of stools directly [7]. It is indicated in patients proposed for abdominoperineal resection post-neoadjuvant, benign lesions with extensive sphincter involvement, extensive or intractable stenosis after perineal radiotherapy. This procedure is reserved for young or older patients in good physical condition, good cognitive level and without indication of postoperative radiotherapy [8].

\section{Patients and Methods}

Study descriptive, prospective and cross-sectional that included 10 patients staged III post neoadjuvant therapy, who underwent an abdominoperineal resection with perineal colostomy using the technique described in Brazil by Prof. Lázaro da Silva [3] in a period of 10 years, from 2008 to 2018 in patients who attended in the Unit of Coloproctology of Domingo Luciani Hospital in Caracas-Venezuela. We select for this technique patient under 55 years old or higher in good physical condition, with adequate sociocultural level for the understanding and management of the procedure and who is not considered receive postoperative radiation therapy. We describe the surgical technique, complications and evaluated continence divided in: "satisfactory continence"

\section{OPEN ACCESS}

${ }^{*}$ Correspondence:

Elvis Vargas Castillo, Department of Coloproctology, Hospital Domingo Luciani, Caracas, Venezuela, Spain, E-mail: elvisvargasc@hotmail.com

Received Date: 05 Jul 2021

Accepted Date: 16 Jul 2021

Published Date: 20 Jul 2021

Citation:

Amaral IM, Castillo EV, Domínguez A, López S, Chiantera D, Paz MP, et al. Perineal Colostomy Post Amputation of Rectum. Clin Surg. 2021; 6: 3261.

Copyright $\odot 2021$ Elvis Vargas

Castillo. This is an open access article distributed under the Creative Commons Attribution License, which permits unrestricted use, distribution,

and reproduction in any medium, provided the original work is properly

cited. that include (continence to solid or liquid stool, gas incontinence or minimal soiling) and "in satisfactory continence" (Incontinence to solid, liquid or severe soiling) and grade of satisfaction. The statistic was calculated with average and standard deviation of the continuous variables; in the case of nominal variables, their frequencies and percentages were calculated. The results were presented in one and two-entry tables. Of the 10 patients, 8 patients $(80 \%)$ patients with adenocarcinoma of the lower rectum and $2(20 \%)$ patient with carcinoma of the anal canal.

\section{Surgical Technique}

At the end of the conventional Abdominoperineal Resection (APR) following the surgical and oncological principles, the mobilized colon is exteriorized, an adequate length is necessary to reach the perineum without traction and with good vascularity (Figure 1). Subsequently, three valves are constructed, performing circumferential seromiotomies, with a distance of $10 \mathrm{~cm}$ between valves and respecting the mucosa and the mesocolon to avoid devascularization, in order to producing a dilation of the colon by the local denervation and so it acts as a reservoir to contain the stools. The seromiotomies are sutured with discontinuous and invaginating stitch using Vicryl 3-0 (Figure 2). After performing the valves and evaluating vitality, the colon is mobilized to the pelvis and must to reach and surpass the perineum. In order to fill the pelvis and reduce dead space, the proximal valve is placed and fixed to the promontory and the most distal valve at $2 \mathrm{~cm}$ from the edge of the stoma, it is subsequently fixed $1 \mathrm{~cm}$ from the edge of the perineal skin to avoid retraction. Between $6 \mathrm{~cm}$ to $10 \mathrm{~cm}$ of exteriorized colon is left loose outside (Figure 3), for subsequent maturation of the colostomy in 4 to 7 days when necrosis is localized (Figure 4,5). During the first month after surgery, patients are instructed to stay in the orthostatic or decubitus position, avoiding sitting. Patients also are managed by a nutritionist who guides an astringent diet. From the $30^{\text {th }}$ day after surgery, it is indicated to perform washed with one to two liters of warm water, followed by local hygiene with 


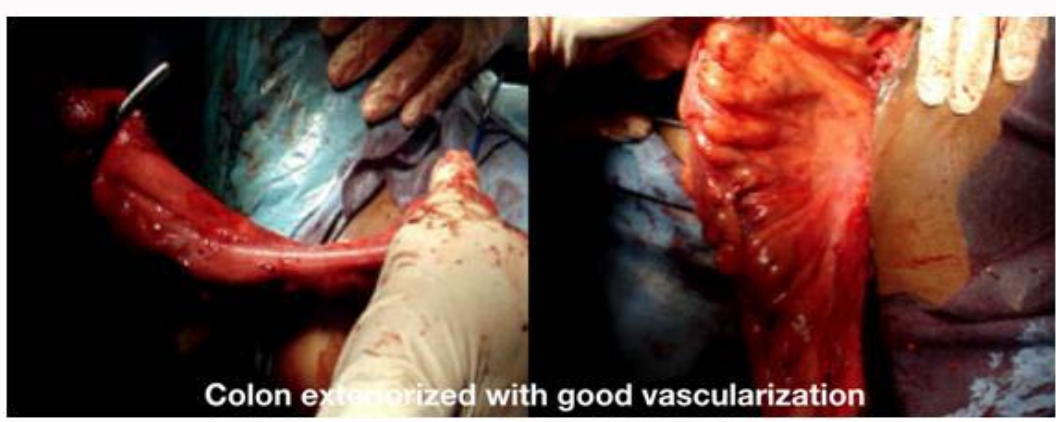

Figure 1: Exteriorization of the vascularized colon.

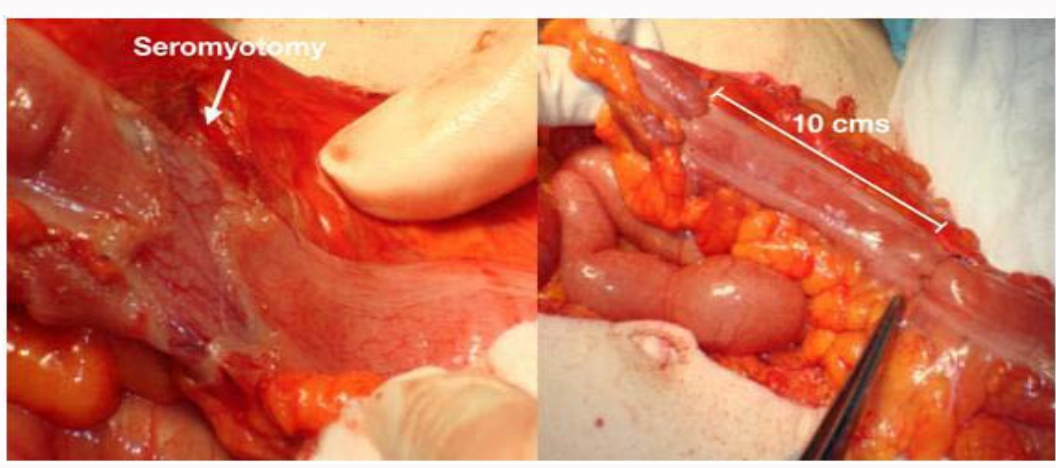

Figure 2: Performing seromiotomies and pseudo valves.

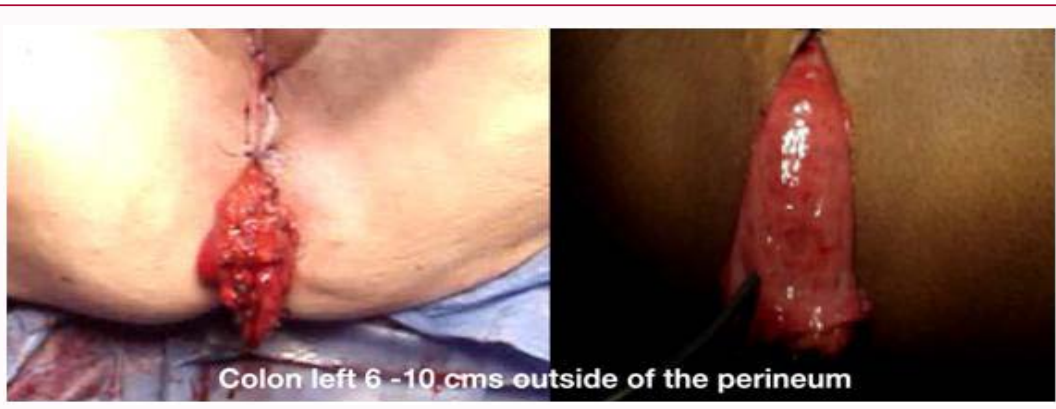

Figure 3: Colon exteriorized and left loose.

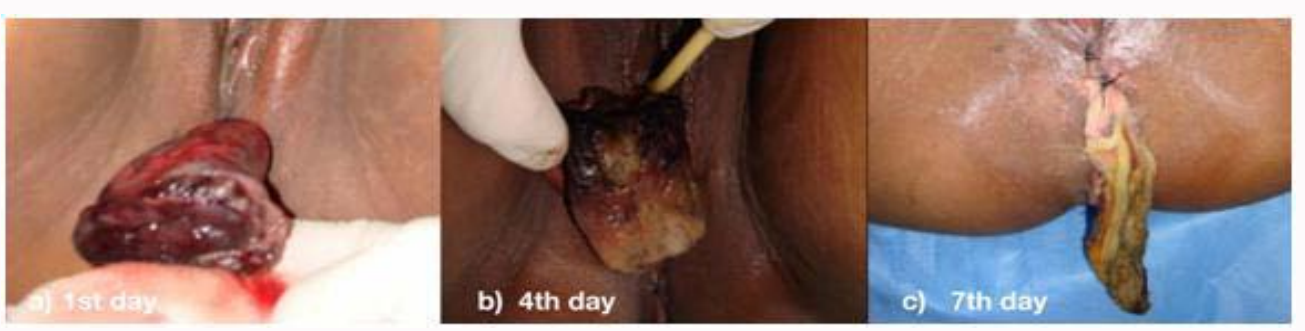

Figure 4: Evolution of necrosis of the exteriorized colon: a. $1^{\text {st }}$ day b. $4^{\text {th }}$ day c. $7^{\text {th }}$ day.

water and soap and the application of an absorbent towel, in order to capture the mucus (Figure 6).

\section{Results}

Six (60\%) patients were male and 4 (40\%) female. Age ranged from 21 to 62 years, with a mean age of 45.3 years. The hospitalization time was 6 to 10 days (7.4 days). Complications occurred in 2 patients (20\%). One patient (10\%) necrosis of the colon that compromised the ostoma with perineal sepsis, 6 days after surgery and 1 (10\%) colostomy prolapse diagnosed at 5 months later (Figure 7) in both patients, the colostomy was reversed. In total, 8 patients $(80 \%)$ tolerated the technique and had control of evacuation and continence with median follow-up was 54 months (11 to 100 months). Currently, in the follow-up of these 8 patients, 2 (25\%) of them, died for different causes than neoplastic disease at 4 and 3 years after surgery and the other are disease-free $83 \%$. Five had satisfactory continence and one important soiling with daily use of pad, further, $83 \%$ (5) defecate with washes every 2 to 3 days and 17\% (1) defecate every 2 days without 


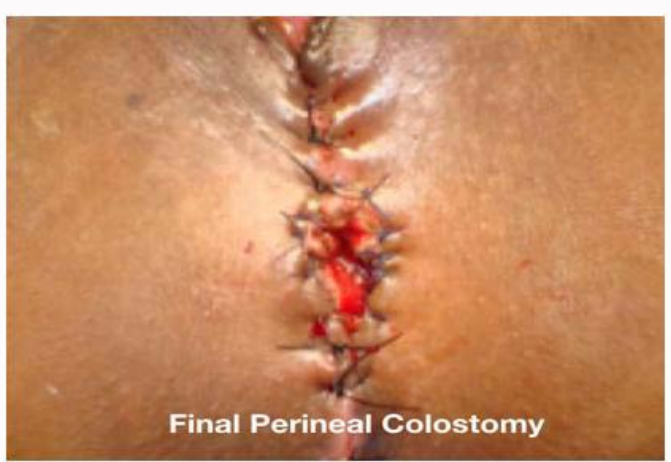

Figure 5: Maduration of the definitive perineal colostomy.

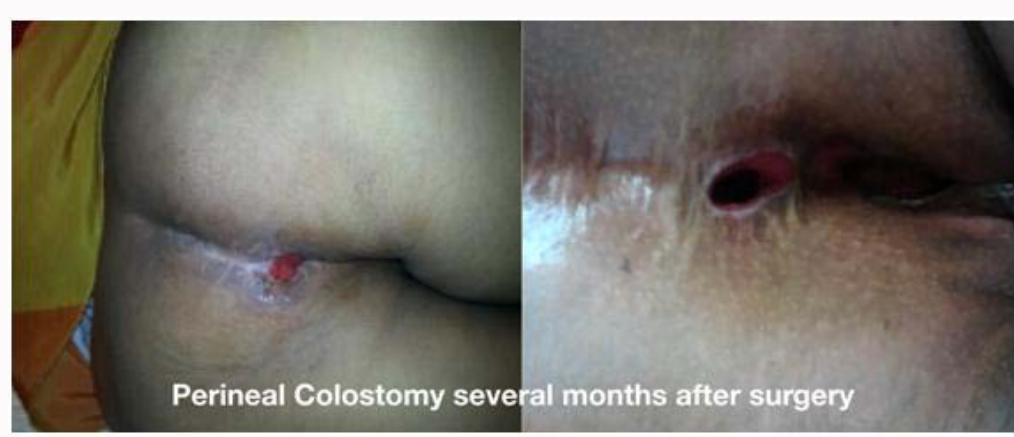

Figure 6: Final appearance of the PC several months after surgery.

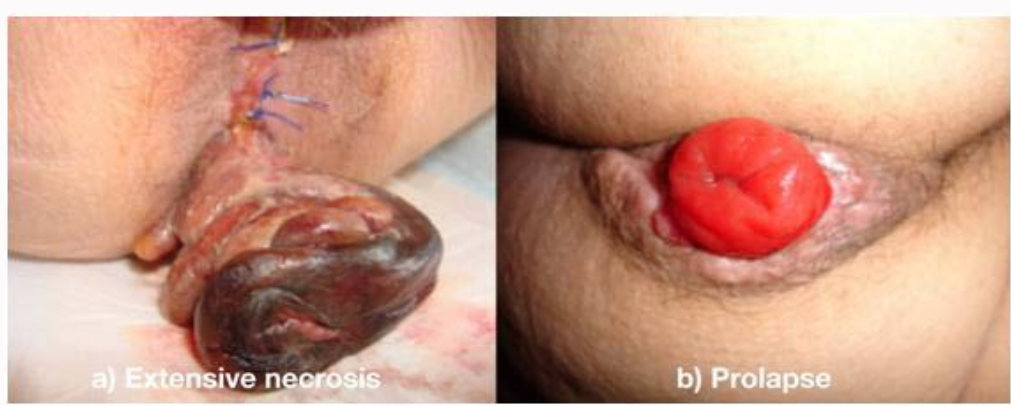

Figure 7: Complications of the PC: a) Extensive necrosis b) Prolapse.

washes (PC performed 4 years ago). 100\% of the patients were highly satisfied with the procedure and continence.

\section{Discussion and Conclusion}

Technique easy to perform, it does not interfere with the oncological parameters of the procedure, only in the way colostomy is performed. Complications are acceptable and can be treated without major inconvenience $[9,10]$. CP is easy to operate and control, with quick adaptation in selected patients, preferably $<55$ years old, providing a satisfactory degree of continence and because not have stoma bag, avoids the social rejection of the iliac colostomy with a high level of satisfaction and a better quality of life.

\section{References}

1. Miles W E. A method of performing abdominoperineal excision for carcinoma of the rectum and of the terminal portion of the pelvic colon. Lancet. 1908;2:1812-3.

2. Camilleri-Brennan J, Steele RJ. Objective assessment of morbidity and quality of life after surgery for low rectal cancer. Colorectal Dis.
2002;4(1):61-6.

3. Cavina E, Seccia M, Chiarugi M. Continenza di colostomia perineale dopo operazione di miles: neosfi ntere elettrostimolato. Boll Soc It Chir. 1985;6:3.

4. Altomare DF, Rinaldi M, Martinelli E, Veglia A, Sallustio P. Perineal colostomy following Miles procedure: from reconstructive surgery to the artificial anal sphincter. Osp Ital Chir 2000;6(6):572-77.

5. Cavina E, Seccia M, Evangelista G. Construction of a continent perineal colostomy by using electrostimulated gracilis muscles after abdominoperineal resection: Personal technique and experience with 32 cases. Ital J Surg Sci. 1987;17:305-14.

6. Gurusamy KS, Marzouk D, Benziger H. A review of contemporary surgical alternatives to permanent colostomy. Int J Surg. 2005;3:193-205.

7. Lázaro-da-Silva A. Amputação abdômino-perineal com colostomia perineal. Ver Bras Coloproctol. 1991;11:105-8.

8. Lázaro da Silva A. Abdominoperineal excision of the rectum and anal canal with perineal colostomy. Eur J Surg. 1995;161:761-64.

9. Gamagami RA, Chiotasso P, Lazorthes F. Continent perineal colostomy 
after abdominoperineal resection: outcome after 63 cases. Dis Colon Rectum. 1999;42:626-30.

10. Lasser P, Dubet P, Guillot JM, Elias D. Pseudocontinent perineal colostomy following abdominoperineal resection: Technique and findings in 49 patients. Eur J Surg Oncol. 2001;27:49-53. 